\title{
TINGKAT KEPUASAN KONSUMEN TERHADAP OBJEK WISATA PANTAI NIRWANA KOTA BAUBAU
}

\author{
Consumer Satisfaction Level To The Tourist Attraction Of Nirwana Beach, \\ Baubau City
}

Winda $^{1}$, Baru Sadarun ${ }^{2}$, dan Akhmad Mansyur ${ }^{3}$

1) Mahasiswa Jurusan/Program Studi Agrobisnis Perikanan FPIK UHO

2) Dosen Jurusan/Program Studi Ilmu Kelautan FPIK UHO

3) Dosen Jurusan/Program Studi Agrobisnis Perikanan FPIK UHO

e-mail: windatakimpo98@gmail.com

\begin{abstract}
ABSTRAK
Penelitian ini bertujuan untuk mengetahui jumlah dan jenis layanan setiap objek wisata dan untuk mengetahui tingkat kepuasan konsumen terhadap setiap layanan objek wisata di Pantai Nirwana Kota Baubau. Penelitian ini dilakukan pada Bulan Agustus 2020. Data diperoleh melalui penyebaran kuesioner, observasi dan dokumentasi menggunakan teknik accidental sampling dengan jumlah responden sebanyak 60 orang. Variabel penelitian yang diamati adalah jumlah dan jenis layanan setiap objek wisata dan tingkat kepuasan konsumen terhadap setiap layanan objek wisata di Pantai Nirwana. Data dianalisis dengan menggunakan analisis deskriptif kualitatif. Hasil penelitian ini menunjukkan ada 3 jenis layanan objek wisata yaitu layanan objek wisata wahana permainan, layanan objek wisata keindahan pantai dan layanan fasilitas penunjang. Tingkat kepuasan konsumen berdasarkan 5 dimensi kualitas pelayanan yaitu tingkat kepuasan untuk layanan objek wisata wahana permainan yang mendapatkan penilaian tertinggi yaitu kehandalan dengan range 3,7 yang menunjukkan kriteria puas. Tingkat kepuasan untuk layanan objek wisata keindahan pantai yang mendapat penilaian tertinggi yaitu bukti fisik dengan range 4,18 yang menunjukkan kriteria puas. Tingkat kepuasan untuk layanan fasilitas penunjang yang mendapatkan penilaian tertinggi yaitu bukti fisik terhadap warung/kantin dengan range 4,55 yang menunjukkan kriteria sangat puas.
\end{abstract}

Kata Kunci : Objek Wisata, Kepuasan, Kualitas Layanan

\begin{abstract}
This study aims to determine the number and type of services for each tourist object and to determine the customer satisfaction level with the services of tourist object in Nirwana Beach, Baubau City. This research was conducted in August 2020. Data were obtained through distributing questionnaires, observation and documentation using accidental sampling technique with a total 60 respondents. The research variables observed were the number and type of services for each tourist object and the customer satisfaction level to each tourist object service at Nirwana Beach. Data were analyzed using qualitative descriptive analysis. The results of this study indicate that there are 3 types of tourist object services, namely service object games facility, services for beach attractions and services for supporting facilities. The customer satisfaction level is based on 5 dimensions of service quality, namely the satisfaction service level for game facility that get the highest rating, namely reliability with a range of 3.7 which indicates the criteria of being satisfied. The satisfaction service level of the beach attraction tourism object that gets the highest rating is physical evidence with a range 4.18 which shows being satisfied. The satisfaction service level of supporting facilities services which get the highest rating namely physical evidence of the canteen with a range of 4.55 which indicates very satisfied.
\end{abstract}

Keyword : Tourist Attraction, Satisfaction, Quality Service 


\section{PENDAHULUAN}

Kajian tentang tingkat kepuasan konsumen terhadap objek wisata pantai merupakan penilaian terhadap perasaan wisatawan yang dapat diperoleh dari tempat wisata. Pantai Nirwana merupakan salah satu objek wisata terkenal di kota Baubau, Sulawesi Tenggara, yang berada di Kelurahan Sulaa, Kecamatan Betoambari. Jaraknya sekitar Sembilan kilometer dari pusat Kota Baubau, akses untuk menuju ke objek wisata Pantai Nirwana tergolong mudah karena jalan yang dilalui adalah jalanan beraspal dan dapat ditempuh dalam waktu yang tidak terlalu lama. Fasilitas yang dapat dipergunakan ke objek wisata Pantai Nirwana adalah kendaraan pribadi atau kendaraan sewa yang berupa mobil penumpang dan ojek yang dapat mengantar pengunjung langsung ke Pantai Nirwana.

Nirwana mempunyai arti surga, dinamakan pantai Nirwana karena keindahan yang ditawarkan pantai ini sangat mempesona, sehingga membuat siapapun yang berkunjung kesini serasa berada di surga. Pantai Nirwana mempunyai hamparan pasir pantai yang berwarna putih. Beberapa layanan wisata yang terdapat di pantai Nirwana adalah menikmati panorama alam, menikmati sunset, diving, berjemur, bermain pasir dan berperahu. Fasilitas yang berada dipantai nirwana berupa gazebo, penyewaan alat selam, penyewaan wahana permainan, toilet, musholla, tempat parkir, warung dan Vila Niwana.

Tujuan pemerintah daerah dalam membangun objek wisata pantai Nirwana adalah untuk meningkatkan kesejahteraan masyarakat, memperluas lapangan pekerjaan dan memberikan kontribusi bagi pendapatan daerah. Dalam hal ini, peningkatan kesejahteraan bersumber dari jumlah pengunjung objek wisata yang menikmati layanan yang ada di Pantai Nirwana. Kepuasan adalah perasaan senang atau kecewa seseorang yang berasal dari perbandingan antara kesannya terhadap kinerja (atau hasil) suatu produk dan harapan-harapannya (Efendi dan Lili, 2016). Para pengunjung yang puas akan rela mengeluarkan dana untuk setiap layanan yang ada, sebaliknya jika pengunjung merasa tidak puas dengan layanan yang ada disetiap objek wisata maka dikhawatirkan para pengunjung tidak datang berkunjung untuk kali berikutnya.

Mengacu pada pandangan tersebut maka untuk pengelolaan wisata Pantai Nirwana perlu mengedepankan tingkat kepuasan pengunjung pada setiap layanan objek wisata. Sebaran tingkat kepuasan dimaksud maka diharapkan dapat memberikan kontribusi bagi penentuan tingkat penunjangan objek wisata pantai Nirwana secara efisien. Dengan demikian maka perlu dilakukan penelitian dengan judul Tingkat Kepuasan Konsumen Terhadap Objek Wisata Pantai Nirwana Kota Baubau.

Pariwisata adalah serangkaian kegiatan perjalanan yang dilakukan oleh perorangan atau keluarga atau kelompok dari tempat tinggal asalnya ke berbagai tempat lain dengan tujuan melakukan kunjungan wisata dan bukan untuk bekerja atau mencari penghasilan di tempat tujuan. Kunjungan dimaksud bersifat sementara (1 hari, 1 minggu, 1 bulan) dan pada waktunya akan kembali ke tempat tinggal semula. Jadi ada dua elemen penting yaitu : perjalanannya itu sendiri dan tinggal sementara di tempat tujuan dengan berbagai aktivitas wisatanya. Undang-Undang RI Nomor 9 tahun 1990 menyebutkan bahwa wisata adalah kegiatan perjalanan yang dilakukan secara sukarela serta bersifat 
sementara untuk menikmati objek dan daya tarik wisata (pasal 1 ayat 1). Jadi kegiatan pariwisata adalah kegiatan bersenang-senang (leisure) yang mengeluarkan uang atau tindakan konsumtif (Soedarso $d k k ., 2014$ ).

Tujuan penelitian ini yaitu mengetahui jumlah dan jenis layanan setiap objek wisata di Pantai Nirwana Kota Baubau dan mengetahui tingkat kepuasan konsumen terhadap setiap layanan objek wisata di Pantai Nirwana Kota Baubau.

\section{METODE PENELITIAN}

Penelitian ini dilaksanakan pada Bulan Agustus 2020 yang berlokasi di pantai Nirwana kota Baubau. Penentuan lokasi penelitian dilakukan secara sengaja (purposive), karena pantai Nirwana merupakan salah satu objek wisata yang berada di Kota Baubau.

Populasi adalah semua pengunjung objek wisata pantai Nirwana Kota Baubau. Sedangkan Sampel adalah bagian dari populasi. Dalam penelitian ini jumlah populasi tidak diketahui jumlahnya (populasi tak terhingga). Penentuan jumlah sampel dilakukan dengan teknik accidental sampling yaitu siapa saja yang secara kebetulan bertemu dengan peneliti dan bersedia memberikan data. Pengambilan data dilakukan setiap minggu dengan tiap pengambilan jumlah responden sebanyak 15 orang yang dilakukan dalam waktu 1 bulan sehingga jumlah keseluruhan responden sebanyak 60 orang.

Teknik pengumpulan data dalam penelitian ini terdiri dari penyebaran kuesioner, observasi dan dokumentasi.

Data yang digunakan dalam penelitian ini menggunakan data data primer yang meliputi (kriteria persepsi konsumen yang terdiri dari bentuk fisik, kehandalan, respon, jaminan dan empati. Kriteria jenis layanan yaitu wahana permainan, keindahan pantai, musholla, toilet/kamar mandi, warung/kantin, tempat parkir dan gerbang karcis) dan data sekunder yang yang meliputi (gambaran umum wilayah, seperti ; kondisi geografis dan kondisi demograsi)

Analisis data yang digunakan dalam penelitian ini yaitu : Analisis deskriptif (digunakan untuk mengetahui jumlah dan jenis layanan setiap objek wisata di pantai Nirwana Kota Baubau) dan analisis deskriptif kualitatif (digunakan untuk mengetahui tingkat kepuasan konsumen terhadap setiap jenis layanan objek wisata pantai Nirwana Kota Baubau).

Analisis data yang digunakan untuk menjawab tujuan pertama dari penelitian menggunakan analisis deskriptif digunakan untuk mengetahui jumlah dan jenis layanan setiap objek wisata di pantai Nirwana Kota Baubau. Analisis deskriptif merupakan tehnik analisis yang dipakai untuk menganalisis data dengan mendeskripsikan atau menggambarkan data-data yang sudah dikumpulkan seadanya tanpa ada maksud membuat generalisasi dari hasil penelitian.

Analisis deskriptif menggunakan langkah-langkah sebagai berikut : tahap pengumpulan data, tahap editing, tahap koding, tahap tabulasi, tahap pengujian dan tahap mendeskripsikan data atau pengamatan mengenai masalah yang diteliti yang terjadi dilapangan.

Selanjutnya metode skoring dilakukan berdasarkan pendekatan sebagai berikut (Wijono, 2014). 
Keterangan :

$$
\mathrm{M} e=\frac{\sum X i}{n}
$$

$$
\begin{aligned}
& \mathrm{M} e=\text { rata-rata hitung } \\
& \mathrm{Xi}=\text { nilai } \mathrm{X} \\
& \mathrm{N}=\text { jumlah data }
\end{aligned}
$$

Untuk mengetahui tingkat kepuasan pengunjung obyek wisata pantai Nirwana kota Baubau, menggunakan klas interval dengan rumus statistic distribusi frekuensi sebagai berikut:

a. Range $=$ data terbesar - data terkecil $=$ $5-1=4$

b. Klas Interval Range : jumlah kelas $=4$ : $5=0,8$
Dari hasil kelas interval dapat di tentukan kriteria tingkat kepuasan pengunjung berikut : 1,00-1,79 Sangat Tidak Puas, 1,80 - 2,59 Tidak Puas, 2,60 - 3,39 Kurang Puas, 3,40 - 4,19 Puas, 4,20 - 5,00 Sangat Puas.

\section{HASIL DAN PEMBAHASAN}

\section{Karakteristik Umum Responden}

a. Jenis Kelamin Responden

Jenis kelamin adalah perbedaan antara perempuan dan laki-laki secara biologis sejak seseorang lahir (Suhardin, 2016). Sebaran jenis kelamin dari masingmasing responden dapat disajikan pada Tabel 1.

Tabel 1. Komposisi Responden Berdasarkan Jenis Kelamin

\begin{tabular}{cccc}
\hline No & Jenis Kelamin & Jumlah (Orang) & Persentase (\%) \\
\hline 1. & Laki-laki & 21 & 35 \\
2. & Perempuan & 39 & 65 \\
\hline & Jumlah & 60 & 100 \\
\hline
\end{tabular}

Sumber: Data primer setelah diolah, 2020

Berdasarkan Tabel 1, dapat diketahui bahwa jenis kelamin laki-laki (35\%) dan perempuan (65\%). Meskipun didominasi oleh perempuan akan tetapi tidak dapat dikatakan bahwa objek wisata pantai Nirwana merupakan objek wisata yang lebih banyak dinikmati oleh wisatawan dengan jenis kelamin perempuan seperti yang dinyatakan Keliwar dan Nurcahyo (2015) bahwa antara laki-laki dan perempuan sama-sama memiliki motivasi yang sama untuk melakukan kegiatan wisata.

b. Umur Responden

Responden di Pantai Nirwana yang berumur dibawah 17 tahun, umur 17-23 tahun, umur 24-30 tahun dan umur 31-52 tahun sebaran masing-masing responden dapat disajikan pada Tabel 2.

Tabel 2. Komposisi Responden Berdasarkan Umur Responden

\begin{tabular}{cccc}
\hline No & Umur (Tahun) & Jumlah (Orang) & Persentase (\%) \\
\hline 1. & Dibawah 17 tahun & 7 & 12 \\
2. & $17-23$ tahun & 37 & 62 \\
3 & $24-30$ tahun & 12 & 20 \\
4. & $31-52$ & 4 & 6 \\
\hline & Jumlah & 60 & 100 \\
\hline
\end{tabular}

Sumber : Data primer setelah diolah, 2020

Umur adalah faktor yang mempengaruhi kemampuan fisik dan cara berfikir seseorang dalam bekerja, umur juga merupakan salah satu faktor utama yang 
mempengaruhi dalam pengambilan keputusan dan mengadopsi suatu inovasi baru (Sugiyono, 2014). Berdasarkan hasil penelitian yang disajikan pada Tabel 2, dapat diketahui bahwa jumlah pengunjung pada objek wisata pantai Nirwana didominasi oleh kelompok usia 17-23 tahun (62\%), usia 24-30 tahun (20\%) dan usia 31-52 tahun (6\%). Hal ini dikarenakan pada usia ini orang lebih berenergi dan bersemangat dalam melakukan perjalanan untuk mencari pengalaman baru ke tempat-tempat yang menarik. Hal ini sesuai dengan pernyataan karnati $d k k$ (2017) yang menyatakan bahwa pada umumnya kelompok dengan usia 16-26 tahun adalah merupakan usia dimana orang lebih berenergi, sehingga diperkirakan pada usia ini orang lebih suka melakukan perjalanan untuk mencari pengalaman baru dan mendatangi tempat yang lebih menarik.

\section{c. Pendidikan Terakhir Responden}

Pendidikan terakhir yang dimaksud dalam penelitian ini yaitu pendidikan formal. Adapun pendidikan formal yang dimaksud yaitu Sekolah Dasar (SD), Sekolah Menengah Pertama (SMP), Sekolah Menengah Atas (SMA) dan Perguruan Tinggi. Sebaran tingkat pendidikan masing-masing responden dapat disajikan pada Tabel 3.

Tabel 3. Komposisi Responden Berdasarkan Pendidikan Terakhir Responden

\begin{tabular}{cccc}
\hline No & Pendidikan Terakhir & Jumlah (Orang) & Persentase \% \\
\hline 1. & SD & 6 & 10 \\
2. & SMP & 12 & 20 \\
3. & SMA & 24 & 40 \\
4. & Perguruan Tinggi & 18 & 30 \\
\hline & Jumlah & 60 & 100
\end{tabular}

Sumber : Data primer setelah diolah, 2020

Pendidikan yang dimaksud dalam penelitian ini adalah pendidikan formal. Adapun pendidikan formal yang dimaksud yaitu dari tingkat pendidikan SD, SMP dan SMA. Semakin tinggi pendidikan sesesorang maka semakin banyak ilmu yang didapatkan. Hal ini sesuai dengan Muhardi (2004) yang menyatakan bahwa pendidikan mempunyai kontribusi yang sangat berharga dan signifikan dalam meningkatkan kualitas suatu bangsa tentunya juga bagi bangsa Indonesia.

Berdasarkan Tabel 3, tingkat pendidikan terakhir relatif didominasi oleh SMA (40\%) dan disusul dengan perguruan tinggi $(30 \%)$. Tingkat pendidikan dapat berpengaruh terhadap jenis aktifitas wisata yang akan dilakukan serta permintaan terhadap kualitas pelayanan yang akan ditawarkan. Hal ini sesuai dengan pernyataan Dwiputra (2013) yang menyatakan bahwa tingkat pendidikan dapat menjadi salah satu faktor pertimbangan terhadap permintaan, dimana tingkat pendidikan mempengaruhi pada aktivitas kegiatan, pelayanan dan kualitas fasilitas di objek wisata.

d. Pekerjaan Responden

Berdasarkan jenis pekerjaan dapat dikategorikan dalam 6 jenis yaitu : pegawai/karyawan (baik negeri maupun swasta), wiraswasta, professional (freelance, pengacara, kontraktor dan sebagainya), mahasiswa/pelajar, lainnya (ibu rumah tangga, belum memiliki pekerjaan dan lanjut usia). Sebaran klasifikasi jenis pekerjaan dari masingmasing responden dapat disajikan pada Tabel 4. 
Tabel 4. Klasifikasi Responden Berdasarkan Pekerjaan

\begin{tabular}{cccc}
\hline No & Jenis pekerjaan & Jumlah (orang) & Persentase (\%) \\
\hline 1. & Pelajar/Mahasiswa & 26 & 43,33 \\
2. & Karyawan/pegawai & 5 & 8,33 \\
3. & PNS & 3 & 5 \\
4. & Honorer & 5 & 8,33 \\
5. & Wiraswasta & 3 & 5 \\
6. & Belum Memiliki Pekerjaan & 18 & 30 \\
\hline & Jumlah & 60 & 100
\end{tabular}

Sumber : Data Primer Setelah Diolah, 2020

Berdasarkan Tabel 4, pengunjung objek wisata pantai Nirwana berdasarkan jenis pekerjaannya didominasi oleh mahasiswa/pelajar $(43 \%)$ dan disusul oleh belum memiliki pekerjaan (30\%), hal ini karenakan mayoritas yang berkunjung untuk mencari pengalaman baru atau cenderung lebih suka berkumpul bersama teman-teman. Hal ini sesuai dengan pernyataan Dwiputra (2013) yang mengatakan bahwa mayoritas wisatwan yang berkunjung ke objek wisata adalah yang suka mencari pengalaman baru yaitu pelajar dan mahasiswa, kelompok ini juga banyak berdatangan bersama teman pelajar/mahasiswa.

\section{e. Tempat tinggal/ Alamat Responden}

Responden yang berkunjung di Pantai Nirwana berasal dari Baubau, Sampolawa dan Kendari. Sebaran masing-masing responden berdasarkan tempat tinggal/alamat dapat disajikan pada Tabel 5.

Tabel 5. Tempat tinggal/Alamat Responden

\begin{tabular}{cccc}
\hline No & Tempat tinggal/alamat & Jumlah (Orang) & Persentase (\%) \\
\hline 1. & Baubau & 56 & 93 \\
2. & Sampolawa & 3 & 5 \\
3. & Kendari & 1 & 2 \\
\hline & Jumlah & 60 & 100 \\
\hline
\end{tabular}

Sumber : Data primer setelah diolah, 2020

Berdasarkan Tabel 5, pengunjung objek wisata pantai Nirwana didominasi oleh pengunjung lokal (93\%) hal ini dikarenakan akses untuk ke objek wisata pantai Nirwana lebih mudah untuk ditempuh. Hal ini sesuai dengan pernyataan Keliwer dan Nurcahyo (2015) yang menyatakan bahwa jarak tempuh (akses) menjadi salah satu faktor yang turut menentukan kunjungan pengunjung kesuatu objek wisata.

\section{Jenis Layanan Objek Wisata}

2.1 Wahana permainan

Jenis layanan dari objek wisata wahana permainan yaitu banana boat, ban, sampan/perahu dan snorkeling atau diving. Sebaran jumlah pemilik dapat disajikan pada Tabel 6 . 
Tabel 6. Layanan objek wisata wahana permainan

\begin{tabular}{cccc}
\hline No & $\begin{array}{c}\text { Jenis layanan objek } \\
\text { wisata }\end{array}$ & Jumlah (pemilik) & Persentase (\%) \\
\hline 1. & Banana boat & 1 & 2 \\
2. & Ban & 28 & 74 \\
3. & Sampan/perahu & 9 & 24 \\
4. & Snorkeling atau Diving & - & - \\
& Jumlah & 38 & 100 \\
\hline
\end{tabular}

Sumber : Data primer setelah diolah, 2020

Berdasarkan Tabel 6, wahana permainan yang di pantai Nirwana terdiri dari Banana boat yang digunakan untuk berselancar, menikmati angin laut dan menikmati pemandangan laut dari sudut yang berbeda, biaya penyewaan banana boat Rp20.000/orang dengan kapasitas muatan 6 orang dapat berkeliling sebanyak 3 kali. Ban digunakan untuk berenang, dengan biaya penyewaannya tergantung pada ukuran ban, biaya penyewaan ban ukuran kecil Rp5000/ban, ukuran sedang Rp10.000/ban dan ukuran besar Rp20.000/ban. Sampan/perahu digunakan untuk melihat terumbu karang, untuk menyimpan barang yang ingin bersnorkeling, dengan biaya penyewaan Rp30.000.

\subsection{Keindahan pantai}

Pengunjung Pantai Nirwana dapat menikmati air laut yang biru, pasir putih, ombak yang tenang, pemandangan terumbu karang dan dapat menikmati fenomena sunset dan sunrise, daya tarik utama objek wisata adalah pemandangan pantai, hal ini sesuai dengan pernyataan Latupapua (2011) bahwa nilai potensi pemandangan pantai yang indah sangat menentukan minat wisatawan sehingga menambah kenyamanan wisatawan untuk datang berkunjung dan menikmatinya.

\subsection{Layanan fasilitas penunjang}

Layanan fasilitas penunjang yang berada di Pantai Nirwana terdiri dari musholla, toilet/kamar mandi, warung, lokasi parkir, gerbang karcis dan gazebo. Sebaran jumlah fasilitas penunjang dapat disajikan pada Tabel 7.

Tabel 7. Jenis layanan fasilitas penunjang

\begin{tabular}{cccc}
\hline No & Layanan fasilitas penunjang & Jumlah & Persentase (\%) \\
\hline 1. & Musholla & 1 & 0,5 \\
2. & Toilet/kamar mandi & 56 & 28 \\
3. & Warung & 28 & 14 \\
4. & Lokasi parker & 1 & 0,5 \\
5. & Gerbang karcis & 1 & 0,5 \\
6. & Gazebo & 113 & 56,5 \\
& Jumlah Keseluruhan & 200 & 100 \\
\hline
\end{tabular}

Sumber : Data Primer Setelah Diolah, 2020

Berdasarkan Tabel 7, layanan fasilitas penunjang sangat diperlukan karena dengan adanya fasilitas penunjang yang ada dipantai Nirwana dapat memudahkan pengunjung untuk memenuhi kebutuhan selama berkunjung kepantai Nirwana. Hal ini sesuai dengan pernyataan Rosita $d k k$ (2016) yang mengatakan bahwa fasilitas penunjang pada dasarnya merupakan sarana yang bersifat sebagai pelengkap utama 
sehingga wisatawan terpenuhi apapun kebutuhan selama mengunjungi.

\section{Tingkat kepuasan konsumen terhadap jenis layanan}

Tingkat kepuasan konsumen terhadap kehandalan dari jenis layanan objek wisata yaitu layanan objek wisata wahana permainan, layanan objek wisata keindahan Pantai dan fasilitas penunjang Sebaran masing-masing responden dapat disajikan pada Tabel 8.

Tabel 8. Tingkat kepuasan konsumen terhadap kehandalan layanan objek wisata Pantai Nirwana

\begin{tabular}{ccccccccc}
\hline No & $\begin{array}{c}\text { Jenis Layanan } \\
\text { Fasilitas Penunjang }\end{array}$ & STP & TP & KP & P & SP & Jumlah & Persentse (\%) \\
\hline 1 & Wahana Permainan & 3 & 5 & 13 & 25 & 14 & 222 & 3,7 (Puas) \\
2 & Keindahan Pantai & 1 & 1 & 7 & 34 & 17 & 245 & 4,08 (Puas) \\
3 & Gazebo & 3 & 5 & 9 & 37 & 6 & 218 & 3,63 (Puas) \\
4 & Musholla & 2 & 6 & 11 & 27 & 14 & 225 & 3,75 (Puas) \\
5 & Toilet & 2 & 3 & 16 & 29 & 10 & 222 & 3,7 (Puas) \\
6 & Warung/kantin & 1 & 4 & 12 & 38 & 5 & 222 & 3,7 (Puas) \\
7 & Tempat Parkir & 1 & 12 & 5 & 30 & 12 & 220 & 3,66 (Puas) \\
8 & Gerbang Karcis & 2 & 9 & 15 & 22 & 12 & 213 & 3,55 (Puas) \\
\hline
\end{tabular}

Sumber : Data primer setelah diolah, 2020

Tingkat kepuasan untuk layanan objek wisata wahana permainan di objek wisata Pantai Nirwana dari kelima dimensi yang digunakan mendapatkan penilaian tertinggi yaitu kehandalan dengan range 3,7 yang menunjukkan kriteria puas, dengan pengunjung yang merasa tidak puas 5 orang, hal ini karena pengu njung merasa fasilitas wahana permainan masih kurang dan wahana permainan yang ada hanya sedikit, sehingga perlu menambahkan fasilitas wahana permainan air agar para pengunjung dapat melakukan berbagai aktivitas dilaut sambil menikmati pemandangan laut. Hal ini sesuai dengan pernyataan Susilawati $d k k$., (2016) bahwa ketersediaan sarana dan prasarana suatu objek wisata tentu sangat mendukung kemajuan objek wisata. Sedangakan yang menjawab puas 25 orang, hal ini karena responden merasa puas dengan fasilitas keamanan yang yang disediakan oleh pemilik wahana permainan, fasilitas keamanan tersebut berupa jaket pelampung saat menggunakan wahana permainan air. Hal ini sesuai dengan pernyataan Suharto (2016) bahwa keamanan pengunjung diprediksikan akan memberikan kontribusi pada peningkatan pengunjung selanjutnya dan merupakan faktor pendorong terciptanya tanggung jawab sosial kepada masyarakat (company sosial responsibility atau $\mathrm{CSR})$.

Tingkat kepuasan konsumen terhadap bukti fisik dari jenis layanan objek wisata yaitu layanan objek wisata wahana permainan, layanan objek wisata keindahan Pantai dan fasilitas penunjang Sebaran masing-masing responden dapat disajikan pada Tabel 9. 
Tabel 9. Tingkat kepuasan konsumen terhadap bukti fisik layanan objek wisata Pantai Nirwana

\begin{tabular}{ccccccccc}
\hline No & $\begin{array}{c}\text { Jenis Layanan } \\
\text { Fasilitas Penunjang }\end{array}$ & STP & TP & KP & P & SP & Jumlah & $\begin{array}{c}\text { Persentse } \\
(\%)\end{array}$ \\
\hline 1 & Wahana Permainan & 3 & 5 & 13 & 25 & 14 & 222 & 3,7 (Puas) \\
2 & Keindahan Pantai & 1 & 1 & 7 & 34 & 17 & 245 & 4,08 (Puas) \\
3 & Gazebo & 3 & 5 & 9 & 37 & 6 & 218 & 3,63 (Puas) \\
4 & Musholla & 2 & 6 & 11 & 27 & 14 & 225 & 3,75 (Puas) \\
5 & Toilet & 2 & 3 & 16 & 29 & 10 & 222 & 3,7 (Puas) \\
6 & Warung/kantin & 1 & 4 & 12 & 38 & 5 & 222 & 3,7 (Puas) \\
7 & Tempat Parkir & 1 & 12 & 5 & 30 & 12 & 220 & 3,66 (Puas) \\
8 & Gerbang Karcis & 2 & 9 & 15 & 22 & 12 & 213 & 3,55 (Puas) \\
\hline
\end{tabular}

Sumber : Data primer setelah diolah, 2020

Tingkat kepuasan untuk layanan objek wisata keindahan pantai di Pantai Nirwana dari kelima dimensi yang digunakan mendapatkan penilaian tertinggi yaitu bukti fisik dengan range 4,18 yang menunjukkan kriteria puas, pengunjung yang merasa tidak puas berjumlah 1 orang hal ini karena pengunjung merasa kebersihan di Pantai Nirwana kurang bersih sehingga menyebakan keindahan pantai berkurang, daerah lingkungan pantai perlu dijaga kebersihannya. Hal ini sesuai dengan teori yang di sampaikan oleh Amirullah (2016) bahwa perlu menjaga kebersihan lingkungan daerah tempat wisata serta sarana pendukungnya dan juga menjaga lingkungan yang bebas dari polusi udara akibat asap kendaraan, rokok dan lain sebagainya. Sedangkan yang menjawab puas 27 orang, pengunjung merasa puas karena persepsi tentang keindahan yang ada di Pantai Nirwana sesuai dengan kenyataan yang di bayangkan. Hal ini sesuai dengan pernyataan Permatasari $d k k$ (2019) bahwa kenyataan yang diterima oleh konsumen sama dengan apa yang dibayangkan sebelumnya sehingga konsumen merasa puas dengan yang mereka dapatkan pada wisata.

Tingkat kepuasan untuk layanan fasilitas penunjang di Pantai Nirwana dari kelima dimensi yang mendapatkan penilaian tertinggi yaitu bukti fisik terhadap warung/kantin dengan range 4,55 yang menunjukkan kriteria sangat puas, pengunjung yang menjawab tidak puas 11 orang, hal ini karena pengunjung merasa harga jajanan yang ada di Pantai Nirwana tergolong agak mahal selain karena harga pengunjung juga merasa tidak puas karena jajanan yang ada di Pantai Nirwana hanya menyediakan snack-snack tidak menyediakan makanan berat. Sedangkan pengunjung yang menjawab puas 21 orang, pengunjung merasa puas karena layanan yang diberikan oleh pemilik warung sangat baik. Harga dan pelayanan yang diberikan kepada konsumen bisa menjadi faktor penentu kepuasan konsumen. Hal ini sesuai dengan pernyataan Shinta (2016) bahwa selain harga, pelayanan juga menjadi faktor penentu kepuasan pelanggan. Pelayanan konsumen adalah suatu perilaku yang ditujukan oleh penjual sesuai dengan yang diinginkan oleh pembeli dalam rangka memuaskan kebutuhan dan keinginannya, semakin baik pelayanan yang diberikan akan meningkatkan kepuasan pelanggan.

\section{SIMPULAN}

Berdasarkan hasil penelitian yang diperoleh, maka dapat disimpulkan bahwa:

1. Ada 3 jenis layanan objek wisata di Pantai Nirwana yaitu layanan objek 
wisata wahana permainan, layanan objek wisata keindahan pantai dan layanan fasilitas penunjang.

2. Tingkat kepuasan konsumen berdasarkan 5 dimensi kualitas pelayanan yaitu tingkat kepuasan untuk layanan objek wisata wahana permainan yang mendapatkan penilaian tertinggi yaitu kehandalan dengan range 3,7 yang menunjukkan kriteria puas, tingkat kepuasan untuk layanan objek wisata keindahan pantai yang mendapat penilaian tertinggi yaitu bukti fisik dengan range 4,18 yang menunjukkan kriteria puas dan tingkat kepuasan untuk layanan fasilitas penunjang di Pantai Nirwana yang mendapatkan penilaian tertinggi yaitu bukti fisik terhadap warung/kantin dengan range 4,55 yang menunjukkan kriteria sangat puas.

\section{UCAPAN TERIMAKASIH}

Terima kasih kepada Bapak Lurah Kelurahan Sulaa dan seluruh responden atas kesediaannya dan bantuannya dalam memberikan informasi kepada penulis selama penelitian.

\section{DAFTAR PUSTAKA}

Amirullah. 2016. Penerapan sapta pesona di pantai polewali kabupaten poliwali mandar provinsi Sulawesi barat. Jurnal kepariwisataan, 10 (2) : 15-27.

Dwiputra, R. 2013. Preferensi Wisatawan Terhadap Sarana Wisata Di Kawasan Wisata Alam Erupsi Merapi. Jurnal Perencanaan Wilayah dan Kota, 24(1) :35-48.

Keliwar, S dan Nurcahyo, A. 2015. Motivasi Dan Persepsi Pengunjung Terhadap Objek
Wisata Desa Budaya Pampang Di Samarinda. Jurnal Manajemen Resort Dan Leisure. 12 (2) : 1027.

Latupapua, Y. Th. 2011. Persepsi Masyarakat Terhadap Potensi Objek Daya Tarik Wisata Pantai Di Kecamatan Kei Kecil Kabupaten Maluku Tenggara. Jurnal Agroforestri. 6 (2) : 92102.

Muhardi. 2004. Kontribusi Pendidikan Dalam Meningkatkan Kualitas Bangsa Indonesia. Naskah Karya Tulis Ilmiah. 20 (4) : 478-492.

Permatasari, U., Budiyanto Dan Sjamsu A. L. 2019. Hubungan Antara Persepsi Dengan Tingkat Kepuasan Konsumen Pada Lokasi Pariwisata Pulau Bokori Kecamatan Soropia Kabupaten Konawe. J. Sosial Ekonomi FPIK UHO, 4 (3) : 171-177.

Rosita., Marhanah, S dan Hanoum, W. W. 2016. Pengaruh Fasilitas Wisata dan Kualitas Pelayanan Terhadap Kepuasan Pengunjung Di Taman Margawisata Ragunan Jakarta. Jurnal Manajemen Resort dan Leisure, 13 (1) : 1-12.

Shinta, R. D. 2016. Analisis kepuasan konsumen pada pedagang kaki lima di kawasan simpang lima semarang. Jurnal administrasi bisnis, 5 (1) : 13-23.

Sugiyono. 2014. Metode Penelitian Pendidikan Pendekatan Kuantitatif, Kualitatif dan R \& D. Alfabeta. Bandung

Suhardin. 2016. Pengaruh Perbedaan Jenis Kelamin Dan Pengetahuan Tentang Konsep Dasar Ekologi Terhadap Kepedulian Lingkungan. Jurnal Penelitian Pendidikan Agama dan Keagamaan. 14 (1) :117-132. 
Suharto. 2016. Studi Tentang Keamanan

Dan Keselamatan Pengunjung

Hubungannya Dengan Citra

Destinasi (Studi Kasus Gembira

Loka Zoo). Yogyakarta. Jurnal

Media Wisata, 14 (1) : 287-304.

Susilawati., Mappamiring, $\mathrm{H}$ dan

Alimuddin, S. 2016. Strategi

Pengembangan Pariwisata Pantai

Bira Sebagai Sumber Unggulan

Pendapatan Asli Di Daerah

Kabupaten Bulukumba. Jurnal

Administrasi Public, 2 (3) : 351366.

Soedarso., Nurif, M dan Windiani. 2014.

Potensi Dan Kendala

Pengembangan Pariwisata

Berbasis Kekayaan Alam Dengan

Pendekatan Marketing Places

(Studi Kasus Pengembangan

Pariwisata Di Kabupaten

Bojonegoro). Jurnal Sosial

Humaniora, 7(2) : 136-149.

Wijono, D. 2014. Tingkat Kepuasan Pengunjung Objek Wisata Pantai

Kuwaru Sanden Bantul

Yogyakarta. Jurnal

Maksipreneur, 4(1) : 22-35. 